\title{
Management educators in practice: to be critical or not to be critical, that is the question
}

Research Article

Judith Breen*

Waterford Institute of Technology, Ireland

Abstract: The field of management education has been the focus of much debate in recent times regarding the relevancy of its content and process. How we define relevance has implications for all stakeholders of management. As a result, how applicable are the alternative approaches to management education such as critical management education (CME). This research explores how criticality is perceived, experienced, and translated into the everyday practices of critical management educators. The research found that there was a common theme about criticality relating to questioning taken-for-granted assumptions about management and its practices. However, distinctions were made between those whose interests were more theoretically, politically, or practically oriented. From the findings, two critical educator types emerged. These were the critical experientialists and the critical traditionalists. This research provides an understanding of the critical classroom through educator perceptions and practices. In doing so, it enlightens the management educator further as to what it means to be critical.

Keywords: critical; management; education

(C) De Gruyter Open Sp. z 0.0.

\section{INTRODUCTION}

Traditional, managerialist, and American models have been used to describe management education in more recent times. A managerialist management education is described as 'treating management as a morally and politically neutral technical activity' (Grey and Mitev, 1995: 74). These models have been criticised and alternative ones put forward. A critical approach to management education has been called for from various sources. Mintzberg (2004) in his book, 'Mangers not MBAs', questions how effective educational institutions are at educating managers. He calls for a more engaging approach to managing and a more reflective approach to management education. $\mathrm{He}$ asserts further that conventional courses of Master of Business Administration (MBA) overemphasise the science of management. This he believes is evident in education programmes that train students in analysis and technique, leaving a distorted impression of practice. The tensions between theory and practice in business education are not a recent phenomenon. In historic terms, business schools in the 1960s in the US changed from a 'trade school' orientation towards a research-and-discipline-led focus, emphasising rigorous academic research over practically relevant research (Thomas, 2007). Similarly, policy changes were at work in the UK, which led to the establishment of elite business schools such as the London Business School and the Manchester Business School in the 1960s. According to Thomas (2007), this discipline-led focus has led to a gap between academically rigorous research and the production of relevant research directed towards the understanding of the issues and problems faced by managers and the management community. However, US business schools have become leaders in a global education industry and have become the benchmark for European schools (Engwall, 2007).

Bennis and O'Toole (2005) also argue that the actual cause of these tensions can be traced to a dramatic shift in the culture of business schools, namely, a culture of academic excellence, which they believe, has been inappropriately adopted. In this culture, instead of measuring themselves in terms of the competence of their 
graduates, or by how well their faculties understand important drivers of business performance, they measure themselves almost solely by the rigour of their scientific research. As a result, recent critics in business schools have been accused of conducting theoretically grounded but irrelevant research; of doing an inadequate job of preparing students for the business school world; of pursuing curricular fads at the expense of sound educational principles; of being too analytical and not process oriented; of failing to provide sufficient ethical and professional guidance to potential managers; and of responding to the demands of the market by pandering to the business school rankings (Thomas, 2007). It is not surprising, therefore, that some writers have gone as far as to say that management education is in crisis. Podolny (2009) argues that the problems afflicting management education are so deep and widespread that people have come to believe that business schools are harmful to society, fostering self-interested, unethical, and even illegal behaviour by their graduates. He suggests further that management education has contributed to the systematic failure of leadership that led to the current financial crisis. The fact that business schools are not developing skills in critical thinking and moral reasoning has been put forward as a reason for these problems (Podolny, 2009). Ultimately, Podolny argues that a focus on value-based leadership and ethics has not been central to management education. He advocates that business schools need to reinvent themselves and promote behaviour that is consistent with society's values.

\section{RESEARCH CONTEXT AND OBJECTIVES}

In response to these debates, Critical Management Studies (CMS) and Critical Management Education (CME) have been put forward as alternative approaches. Critical Management has been described as having 'an agenda for research, teaching and organisational practice that understands management as a political, cultural and ideological phenomenon, and addresses managers not only as managers but as people, and is attentive to other social groups (subordinates, customers, clients, men and women, citizens in other capacities) whose lives are more or less directly affected by the activities and ideologies of management (Alvesson and Willmott, 2003: 15). However, it is seen as a marginal activity within business schools as most schools are assumed to adopt the more traditional or US model of business education. The field of CMS is still relatively new and it has been suggested that 'more knowledge about the way the everyday life in academia is accounted for by ordinary business-school students and teachers would perhaps make us wiser when it comes to suggesting changes or defending the conditions for 'good work' in academia' (Korpiaho et al., 2007: 58). However, it must be acknowledged that there is a shortcoming in the research to date with regard to local contexts and experiences in the field. However, it is important to define what a CME course includes. It has been associated with writing that challenges the politics of management education and/or experiments with pedagogy and that seeks to minimise harmful power dynamics and/or seeks to raise the critical consciousness of students (Perriton, 2007). For example, a critical approach to education, as advocated by Perriton and Reynolds (2004), would involve

a commitment to questioning the assumptions and taken-for-granteds embodied in both theory and professional practice, and to raising questions about management and education that are moral as well as technical in nature, and are concerned with ends as least as much as with means. (Perriton and Reynolds, 2004: 65)

The paucity of recorded practice on the implementation of critical pedagogy (Reynolds, 1999) highlights the key role of future research in CME. For example, to date, empirical research on studying activity or even student experience in management education is especially rare (Korpiaho et al., 2007). However, there have been some exceptions. These have included studies that have focussed on the impact of CME on learners' attitudes, beliefs, and/or experiences (Choo, 2007a; Collin, 1996; Currie and Knights, 2003; Monaghan and Cervero, 2006; Rigg and Trehan, 1999). Some of the studies have examined the barriers and problems associated with introducing a critical approach. Such studies have examined the experiences of different ethnic groups, e.g. Chinese students (Choo, 2007b) and black women students (Rigg and Trehan, 1999). This research identified that some of the problems were attributable to cultural diversity and learning styles that were incompatible with Western pedagogical assumptions. Moreover, some student experiences in the studies were found to be positive, while others found the experience disempowering (Rigg and Trehan, 1999).

Educator insights have also stressed the importance of managing issues regarding the power of participants, programme structures, and resources (Sinclair, 2007). The management classroom can also reveal the 
emotional and political 'dynamics' of the group and how these create structures for action and inaction (Vince, 2010: 33). Through experiential exercises, Vince (2010) explores ways to address anxiety and politics as an integral part of learning about management. He stresses, however, that 'Business Schools do not encourage reflection on the emotions and politics generated within the practice of management teaching and learning, or more generally within management practice' (Vince, 2010: 28). A common feature of all these studies is that they have focussed predominantly on postgraduate courses and experiences. Undergraduate student experiences have received much less attention. Notable exceptions regarding the use of narrative as a way of engaging students in a critical way include the study by Watson (2007). Other undergraduate experiences include the study by Vince and Reynolds (2007), who describe the topic using an experiential exercise with large student numbers. In contrast, the MBA programme has been at the centre of a lot of this research to date. In addition, a key feature of all of these studies is that they have been conducted in the UK, the US, and Australia (Perriton, 2007). Therefore, not only is the concept and approach underresearched generally in management education but it is also more specifically underresearched outside of these regions. Therefore, it is important to identify the experiences and challenges of embracing a critical pedagogy in management education. Consequently, the aim of this paper is to explore how criticality is perceived and translated into the everyday practices of critical management educators.

\section{RESEARCH METHODOLOGY}

As a practitioner in management education, the research objective was to reflect critically on my own practice. The aim of the research was to inform my everyday work and I therefore decided to investigate critical approaches to management education from an educator perspective. Consequently, the aim of this paper is to explore how criticality is translated into the everyday practices of critical management educators. The research was guided by three main questions:

- What factors have contributed to the adoption of this management philosophy by critical management educators?

- How is criticality perceived by critical management educators?

- How does this alternative management philosophy translate into the professional practice of critical educators?

However, when it came to answering the research question regarding translating their perceptions into practice, there were differences in their orientations towards content and process. Such orientations were a key characteristic of how educators approached their work. Although it is fair to say that all educators focus on both content and process to some extent, it became evident from the findings that some leaned more strongly to one or the other. The research involved using qualitative research methods. The first stage of the research included interviewing educators in the field. The second stage of the research involved observation of educators in practice. A total of 15 semi-structured interviews were conducted with educators in higher education in Britain and Ireland. This stage involved conducting interviews between March and August 2009. Interviews were chosen as a data collection method as it allows the researcher to investigate and prompt things we cannot observe (Wellington and Szczerbinski, 2007). The sample chosen was based on the criteria that the educators had practised and/or written in a critical way. For example, some educators wrote about criticality from a political, theoretical, and/or a practical perspective. Fifteen interviews were included in the study; of these, 13 educators were based in the UK and two were based in Ireland. There were two interviews conducted in Ireland as the field is not as prominent as it is in the UK. The research sample consisted of seven female and eight male participants. This paper will discuss the findings of the interview stage of the research. The convention used has been to report the actual quotes from participants.

\section{EXPLORING THE CRITICAL CLASSROOM}

One of the main themes that emerged from the interview data was the effect that criticality has on teaching practice and the methods used by educators. In the following section, this theme will be discussed. 


\section{What is critical teaching?}

The data analysis includes an exploration with educators during the interview about criticality in their classroom. How does criticality affect their practice? What is critical teaching? In order to understand this further, it is important to first identify where the educators focus their attention in the practice of their teaching, i.e. the content or the process. For example, some educators spoke more about their practice in terms of the content of their subject, whereas others spoke more in terms of the process of their teaching. As a result, it is important to identify the processes that they are engaged in when teaching in a critical way and what influences critical educators in their teaching. Firstly, to understand what critical teaching is, it is important to establish where the educator's focus on criticality is. Many critical educators were interested in the engagement between action and reflection. They were also interested between the content and process - theory and practice (Reynolds, 1997). James articulated that you could not separate the two:

It's the engagement in the process that enables you to transform the content and to re-invent it and re-apply it in different contexts and in different ways. I don't really see that there is a clear distinction between theory and practice in that way or content and process. I think for me they are part of an engagement with the world. (James)

Although all educators focus on both content and process to some extent, it became evident from the findings that some were more oriented towards one or the other. From the findings, six of the educators were more content focussed and nine were more process focussed. It is important to note that focussing on content in a critical way meant different things to different educators. For example, the content could be more politically left wing for some educators than others.

...I see Business Schools as fairly right wing institutions and for me being critical means being left wing. (Robert)

If I am designing criticality as left wing then it doesn't matter how you teach it, what matters is that you teach it. (Noel)

And you have got to be critical not critical from a left wing or right wing political point of view. (Brian)

This more content-focussed group described their teaching as 'conventional', 'traditional', 'old-fashioned', and using the lecture method. This group very often relied on teaching methodologies that were more conventional, i.e. on lectures. Robert, for instance, did not focus at all on the more experiential methods in the classroom. He believed that it was his duty to teach the mainstream business topics and introduce some critical content with it. He did not feel it necessary to explore the more innovative pedagogies. However, within this group, four spoke about the importance of dialogue and engagement within the classroom. David described what this means in his classroom:

It's not just about persuading a bunch of students that what you say is gospel; I mean that's closure. So the sort of criticality that I am interested in demands dialogue. You are wanting to find out exactly where the student is, where their beliefs are and then have a conversation about that. (David)

It was interesting to note that two of these educators who described their critical teaching as more content based and using more of the lecture method referred to themselves as being good at teaching. Perhaps they focussed more on the content of their teaching because they were good at the process of teaching anyway. Noel illustrates this when he describes his teaching. He believes that the lecture is not 'one thing'. He does not see himself as someone who just stands up there reading his PowerPoint presentations. He compares himself to a stand-up comedian who just runs around chats a lot, does impressions up the aisles, and tries to animate the whole thing as much as possible. The stand-up comedian is someone who has interpersonal skills that he admires in terms of making a space work, particularly for big groups. He feels that if you have a lecture theatre with 150 people, you need to be able to shrink it and make each of the students think you are talking to them:

You have to sing and dance a bit. I overwhelm them with energy. I go into the lecture theatre and shout a lot, show them things, make them laugh and do a bit of stand-up comedy and try and interest them in what I am 
doing...Structure is not my thing, for me structure and lesson planning is much less important than inspiring them to want to go to the library. I want them to run out of my class thinking that's a really good thing he was talking about, I am going to find out about it. Do not know if my teaching is critical or not. I think I am a reasonably good teacher but I think that's largely because I am an experienced teacher and I have done it for a long time to lots of different groups. You could just as easy detach my teaching style from the content. I try to spend a lot of time listening to students, trying to get them to talk, be involved and engaged. Again I don't think that there is anything inherently critical about that. I think the criticality for me comes out of the kind of conclusions I try and encourage the students towards and the kind of arguments that I make. (Noel)

Helen also stressed the importance of how you got your message across and she believes that there is a merger between good teaching and being critical. However, Noel was unsure at first as to whether his teaching was critical or not. On reflection, he saw himself as more content focussed than process focussed. However, when he describes his teaching methodology above, the process of his teaching could be described as critical although he would describe it as good teaching. Two of this group of educators also found it difficult to relate to the notion of a critical pedagogy and believed it was more important 'what you teach' rather than 'how you teach'. Robert believed that teaching in this way was self-indulgent and compared such educators as 'hippies playing in the sand pit while the kids want to learn the basics of business'. Critical pedagogy was also seen to be at odds as to what one educator believed to be critical:

I don't think most of the Freire critical pedagogy arguments even apply. Again when I read some of this stuff and I try not to very often, I am unconvinced that they are actually writing about what I understand to be critical. I think they are talking about some interesting teaching styles but I don't see anything necessarily critical about that. If I am designing criticality as left wing then it doesn't matter how you teach it, what matters is that you teach it. I don't stand there and lecture a lot; I try and involve them and all that kind of stuff. I guess I am sending certain kinds of messages about valuing their ideas and opinions. Overall it is much more about content than process for me. (Noel)

It is interesting to note that Elizabeth referred to criticality as hardly ever entering her teaching. She felt that she was more a critically inclined management development practitioner than a critical management educator. She describes human resources (HR) as a much more constraining context in terms of regulations, conformity, quality assurance (QA), class sizes, and assessment regulations. However, she does try to tell students that there is no one proven way of managing HR or doing HR development (HRD) and is a fairly conventional (even old-fashioned) lecturer. She sets lots of readings and expects a high standard of critical engagement with text and theory, i.e. she expects students to critique, in a scholarly way, existing practice and theories of HR. In contrast to Elizabeth, the focus on criticality in practice for nine of the educators interviewed was very much based on the combination of the content and process (Reynolds, 1997). They use 'the here and now of the classroom' as a vehicle to think about organisational relations and self-reflection as a manager (Reynolds and Trehan, 2001). This critical orientation in the classroom is discussed in the next section.

\section{How to be critical in the classroom:action learning}

Having identified that some critical educators focus their teaching more on the process, it is important to identify what processes they engaged in when teaching in a critical way. Also important is what influences critical educators in the teaching process. As action-based learning methodologies were used by seven practitioners, it is important to discuss why and how these are used in the critical classroom. Firstly, from the research findings, the action-based learning sets were used on postgraduate master's courses. There were similarities and differences in their function and assessment methods. The action learning sets were made up of five or six students coming together at regular intervals. One educator also described them as co-operative inquiry groups in conversation about real issues and action coming out of the meetings. On one of the master's programmes, there were no formal lectures or syllabus. Catherine described it as being very unlike traditional programmes. It was workshop lead combined with action learning sets. The students are part of the design. They choose what they want to study and do on the workshop. For example, the students were given five or six readings and there is no compulsion to read them. They submit five separate pieces of work and a dissertation, which is peer assessed. The action learning sets change every time a piece of work is submitted. The students read each other's work and share feedback. They then agree on a mark collectively. Catherine described her students as 'critical friends' challenging the work and paper you are reading. 
When it comes to assessment, she makes sure her marks go in last. The overall mark results out of a process of negotiation and discussion.

In another programme, the action learning sets were used to enable the students to talk about their dissertations. The purpose of the set talk was to elaborate about their research and what it means for them and their organisation. Conversations about how they can put their ideas forward in their organisation and the political insights arising from that were important:

Once you move them into those conversations the penny is struck. Once you have those conversations happening they become more open. Some of the material they have read starts to make sense because they can relate it to their experiences. That takes time to get to that. (Sarah)

The action learning sets were also used for updating progress, getting feedback, students deciding what they want to get out of the set, and other emerging issues. The sessions also acted as an emotional support. The first half hour can be a 'bitch and moan' session, as Sarah's class called it. This time was an opportunity to discuss their frustrations and get them out of the way. Anxiety in the classroom was a theme in the observation stage of the research. It was also spoken about during the interviews. As a result, facilitation and support from the educator is important. Catherine spoke about how some educators who take on such programmes do not give enough thought to the anxiety that it can provoke both among students and can be reflected in the student. However, such anxiety was to be expected in the classroom (Vince, 2010).

As a result, Catherine spoke about the role of co-training before the tutor starts working on such programmes. Catherine was co-trained with another member of staff on a similar programme in a different institution for 3 years. Sally also worked on this programme, which both educators had found to be inspiring and influential in their future careers. The make-up of the staff team was a crucial factor. It was about staff members being comfortable and being able to handle whatever issues surfaced. Catherine believed that you could not just put any staff member on the team. You need to be able to let go of control, which can be difficult, if you are used to being in control as an academic. You also need to be able to work with what is happening in the moment:

If you are used to being in control as a member of an academic staff you have to let go of some of that and it does not come easy or comfortable. So some staff members at ' $x$ ' will put their marks in first, it's their way of controlling it. If you become anxious about it, it can become highly problematic. It's your capacity to work with it as it's happening in the moment... So rather than giving them the theory to start with it's almost like they have the experience and they layer it with some reading that might help them to unpack what was happening in the group. (Catherine)

Due to co-training, Catherine felt like she was a participant on the programme. She could feel the same emotions, anxieties, and questions that the students had. Paul also worked on the same programme and he stressed that the design differed from many university courses. The use of action learning sets allowed for student involvement in the content. They base their assessed work on work of their own choosing. The assessment process also involves the student, as their work is self, tutor, and peer assessed. This was a crucial element of criticality for him as the course assessment was less hierarchical compared to other conventional university programmes.

Three interviewees emphasised the influence of the Tavistok Institute on their work. Two of the interviewees had been influenced by its philosophy earlier in their careers on the same programme that they both worked on. Another educator had been a participant on one of its courses. This influence was evident in how they conduct their current programmes. For example, Sally spoke about how she would be explicit with the students about the philosophy of the course:

I would use terms like Tavistok terminology right from day one. This is a programme that presents there and then' 'here and now'. There and then - your past, the assumptions you bring, the experiences you have. Here and now; now within this room, within this programme in which we will both share some of the challenge. We will deliberate perspective take; take different perspectives to look at the there and then... Use this as a framework to introduce the combination of experience action and challenge. (Sally)

Catherine spoke of drawing from the 'psychodynamic theory' because it helps provide a different lens to help understand the process elements of critical theory. This was about working through the process, doing it with 
confidence and with a real understanding of what is going on in the group. She describes this in relation to the collaborative assessment methods used on a course:

This is not just about a mark. They will see that mark and read that mark in all sorts of ways. You have to understand what games are being played if any in context. I hear I don't mind what mark I get so long as I get a pass. Then I watch and hear what kind of dialogue is coming and it is clearly evident that they do mind what mark they get and where in the pecking order, where people sit. Got interested in how students experience the process and what it actually means for them. Interested in the dynamics in what you talk about, process you work with, the process and content in terms of what the final marks might be. (Catherine)

It is important to acknowledge that some educators used critical methods of teaching in their undergraduate programmes also. However, they mostly spoke about their experiences with teaching postgraduates. One educator discussed using the technique of negotiated narrative. This was a critical technique used with undergraduate students. This is important as many educators raised the point about how difficult it was to teach in a critical way with undergraduate students. The negotiated narrative gave the students an opportunity to express their experience of the world, however different it might be from business practitioners on postgraduate courses:

I'll bring my stories from my ethnographies and research projects. You'll bring your stories from work and we will mix it together with the magical ingredient of organisational theory. Between us from all that lot, we will discuss just how the world works. (Brian)

James also described teaching critically with undergraduates with a group of up to 250 . His use of an experiential exercise highlighted how to be critical with large group numbers. Patrick spoke of getting undergraduate students to think differently by getting them to write reflection notes based on their own work experience. This could range from a supermarket job or club societies. He gets them to tell their own stories. For example, one student said in class 'management doesn't care'. Patrick got the student to question how he had arrived at the conclusion that management does not care. He also uses puzzles and Sudoku in class to help them question their thinking 'how do you know you have the right answer'.

\section{Building and deconstructing learning}

The environment in which learning takes place is an important element of teaching in a critical way. The creation of this learning environment involves both building and deconstruction processes. Firstly, in the interviews, some educators spoke about being explicit about their teaching methods and philosophies with their students. This usually involved educators articulating what these are with the students either verbally in introductory classes and/ or in writing through programme literatures and so on. For example, James describes the process as being like a health warning, i.e. 'this course can seriously enhance your ability to learn'. He is very explicit that the course is very different to what the students are expecting and wanting to learn. He also gives the students a lecture on why he is not going to lecture them. This is to reinforce the message given to the students in the pre-course written material by showing them through a lecture the limitations of lecturing in relation to leadership.

So it's about trying to build people's connection to this form of learning. You have to be careful about creating the right boundaries within which this type of learning is done. You can't jump into the classroom you know without preparing the space both conceptually and physically in a way that is important in creating the right kind of boundaries. (James)

Brian expressed how he is explicit from the start with his students about his position. He describes himself as a critical scholar and how he communicates this with his students:

...my pitch is we have got to question the taken for grantedness of everything we do. Now if you work with me in this workshop today I am going to challenge and question a lot of what you take for granted and you will be better placed to do your jobs afterwards and it works. They come back only for more. That's only in part because I have got that credibility because they know and they can see in the literature that I have been right in there and done their job. I say I am a sociologist, a researcher. I am a qualified practitioner as well and when I am critical of a lot 
of practices, l'm not doing it from some arrogant political or academic point of view; I'm doing it from a solid and social science point of view. Where's the evidence, does that work, is that credible. (Brian)

Being a social scientist was also at the heart of his teaching and research. Evaluating the research about business and management and presenting it as an account of what goes on was spoken about. He used Maslow's motivation theory to explain, as seen in the following:

I can show from my research that Maslow's motivation theory is rubbish and I teach it. You really ought to know about it....but when you look at what managers do and try this as a manager, it's totally unsuccessful. I know people who go in and teach it... have got to teach the mainstream stuff and are then dishonest with it. If you take the view that you are a social scientist investigating the world of management then you don't have to go along with the values of the worst mainstream management stuff but neither do you have to stand up there and speak contemptuously of managers, which I'm afraid too many CMS people do. (Brian)

On a number of occasions, educators spoke about how they tell students what they should expect and also what not to expect. For these educators, their teaching was not going to be about giving students prescriptive lists and so on:

I tell them if they came to learn about techniques and principles then that's not what the course is about. They could just take up a book and read. The course is about thinking differently about leadership. (James)

Patrick is also explicit about his course at the beginning: 'if you want to know what this course is about it is about you'. The deconstruction of existing learning experiences is seen when he speaks of 'I am sabotaging the educational system they have been part of. I am saying start with experience, write about the organisation they are in, purely reflective, write their own stories'. They are not used to this, as they are more familiar with learning what is in the textbook. He teaches them to ask their own questions. The experiences that they write are the ones that puzzle them. When they ask him, 'should I write about this', he says, 'if you are asking me, you haven't got it yet'. However, even though he tells them at the beginning what to expect, he believes that it does not mean anything at first and that it is something that usually emerges during the course.

However, for some educators, how explicit they were about communicating their position depended on the type of course or module they were teaching. For example, at the master's level, Tracy explains why she has designed the course the way it is designed. However, this does not happen in all her classes:

If I'm teaching mainstream $O B$ I wouldn't do that, I might bring in questions for consideration. I wouldn't say that this is from a critical or postmodern perspective. It would be embedded as a practice in the classroom. At master's level students do need to understand the assumptions underlying particular perspectives so we would actually talk about those things. (Tracy)

Some educators were less explicit about their positions as an educator to their students. For both Helen and Lily, it was sometimes gradually communicated as the module emerged through the introduction of course material. For others, it was about the importance of building connections with the students' learning through their teaching technique. For example, announcing a 'left wing position would turn students off'. Instead, the students were influenced through the teaching technique first to engage them:

I don't announce my ideological presuppositions at the beginning but what I do is try and almost kind of explode with force of personality to tell them it's the most important course they will ever do. ...I don't say I am left wing and I believe in these particular things ...I allow that to emerge in the class. If I started off saying I am a left wing nutcase the students would almost certainly turn off they would not listen to me. If I start off by saying we are going to have a tremendous amount of fun talking about really important things then I much more likely to get them. That's as much salesmanship as teaching. A really good teacher is someone who sells themselves first then hopefully gets students on the rebound. (Noel)

It is also interesting to note that Noel could not say at first whether his teaching was critical or not. He spoke of the importance of content over the process. However, later in the interview, he acknowledged that the process was 
important and that for him, he thought he was half way in between. The process as he describes it seems to be very important in getting his message across:

I do think the best teachers I've seen and experienced are people who light up the space like fireworks. People who excite you with the things that they do. It doesn't mean that they need to be announcing that they are going to be left wing firebrands. It means that they have to be good at selling what they do. (Noel)

This process of building people's connection to this form of learning may also involve a deconstruction of existing learning approaches that the students are familiar with. This deconstruction of existing learning approaches was observed in the second stage of the research through observation of the educator in action. He deconstructed previous learning approaches by showing the limitations of lecturing and using experiential exercises throughout the module. As a result, the creation of the learning environment, which involves building connections to critical learning, is also an essential element in the process of critical teaching. Resistance from students could also be an outcome of the critical process. However, such resistance was often to be expected by educators and part of the process. Such resistance could come from anxiety and an unwillingness to learn. However, such critical programmes were seen to give the students guidance and the opportunity to explore the feelings that emerged. The dynamics of the group could often help others with such struggles. However, it could take time for students to see the value of critical learning. Reflection papers and verbal feedback were found to be useful in understanding student experiences of the learning process. Student testimonials later on in their careers often told a different story to the student's original experience. The perceived value and relevancy of being in a critical classroom may not always be immediate.

The above sections also highlight the critical effect on teaching practice for educators. They highlight where the critical educator's orientation is towards: the content or the process of their practice. From the findings, six of the interviewees mostly focussed on the content of their practice. For them, the process is perceived as being much less of a focus, even though four of them discussed the importance of dialogue in the classroom. However, it was interesting to note that two of these educators described themselves as being good at what they do. Perhaps, in practice, the process was just as important in getting their message across to students, but they perceived the content as their main focus. It was also interesting to note that nine educators focussed more on the process of their teaching. Seven of these discussed the importance of action learning in their practice. The use of action learning was at the heart of the critical process in the classroom for these educators. There were similarities and differences in their function and assessment methods. However, three educators spoke about the influence of the Tavistok Institute and the psychodynamic theory in their practice. The process of building connections with the students' learning through communicating the position of the educator or expectations was also important. Some educators did this early on with their students through verbal or written communication. Others let this emerge through the process of their teaching. From the data analysis, two ideal types of critical practice emerged. These were the Critical Experientialists and the Critical Traditionalists. These are based on the educators' management education orientations. Their orientation is based on two dimensions:

- Content or process

- Traditional or critical

The content or process dimension relates to an emphasis on what or how they practise. The traditional or critical dimension relates to their orientation to process. Traditional process includes using more of the lecturing method and critical process includes using more experiential teaching methodologies. The following is a summary of both critical educator ideal types.

- Critical experientialist (type 1). The characteristics of this type of educators are that they use both critical content and critical process in their teaching. However, the process of their teaching is just as important as the critical knowledge that they are sharing. They engage with experiential learning, which can include action learning and reflection. This type of educator emerged from the findings of the study and represented nine of the educators (Figure 1). The value of this approach is that the classroom dynamics of action learning and other experiential exercises can be powerful in creating an organisation in the classroom. Such an approach has also the potential to raise questions about management practice and its relationship with society. The observation findings also highlighted how a different understanding of learning can be generated using this approach. The role of the tutor is paramount in creating this environment both conceptually and physically. In addition, the potential for learning communities to develop inside and outside the classroom can arise. 
- Critical traditionalist (type 2). The characteristics of this type of educators are that they prefer to use a critical content in their teaching but remain loyal to the more traditional process of learning, e.g. lecturing. They are less interested in and/or unfamiliar with experiential techniques. Their focus is on the critical content of their teaching. They emphasise a more theoretical and/or political focus in their practice. This type of educator emerged from the findings of the study and represented six of the educators (Figure 1). The value of such an approach can help educators and students reveal the complexities of management and its impact on society. Such an approach to critical content also exposes the student to a side of management that is either less prominent or non-existent in mainstream approaches.

Figure 1. Critical educator type

\begin{tabular}{cccc}
\hline Critical educator type & Research sample $(\mathbf{n}=\mathbf{1 5})$ & Content & Process \\
\hline \hline Critical experientialist & 9 educators & Critical & Critical \\
Critical traditionalist & 6 educators & Critical & Traditional \\
\hline
\end{tabular}

It is important to acknowledge that other educator pedagogies such as those by Giroux (1981) and adapted by Reynolds (1997) have also explored the relationship between content and process. The research provides further evidence of this relationship in the field of management education. However, Reynolds describes pedagogy as radical, whereas in the critical educator types above, the word radical is not used. The reason for this is that the findings did not suggest that the educators used the language of being radical when describing their critical practice. Therefore, it is appropriate that the ideal types reflect the educators' practice in the language used as well as the practice. The significance of the ideal types is that they reflect critical management educators' orientations to their field. It also enables us to examine and question as follows - what I am teaching? why am I teaching it? how am I teaching it, why this way? and in whose interests am I teaching? (McLean, 2006).

In answering the research questions regarding perceptions and experiences in the field, the findings from the interviews conducted suggest a number of factors to consider when engaging in a critical approach. Such factors would be useful to educators to inform their practice. The factors are particularly relevant to those who might be considering adopting a critical approach. Therefore, as a potential emergent critical practitioner, what might those factors be?

\section{How do you identify yourself as a critical educator?}

From the findings, it was established that there are many perceptions of being critical. As an educator who wishes to pursue this approach, what might your critical approach be? What kind of critical management educator do you aspire to be? Do you engage with criticality with a capital $C$ and $T$ or small $c$ and small $t$ ? Do you take a political perspective or a more pluralistic one? Will you call yourself a CMS, CME, critter, critter-lite, critical realist, or pragmatic realist? Will the label provide 'a nice home a protective belt' to work within. Will it be useful in helping you to 'network, belong, articulate, and debate'? Maybe you would rather not be identified by any label (Hancock, 2008), as you don't want to privilege one position over another. Ultimately, what critical management educator type are you? When it comes to teaching critically, educators were found to focus on content or process. Are you more content focussed or process focussed? From the ideal types above, will you be a critical traditionalist or a critical experientialist?

\section{How will you be perceived?}

How critical educators perceive themselves and others within the critical community was often referred to. Their critical identity was a theme throughout the research. Some people made distinctions between themselves and other people in the critical community. Distinctions were also made between those who were more influenced by critical pedagogy and those who were more theoretically and politically influenced. Others were of the opinion that being critical involved a more pluralistic approach (Fournier and Grey, 2000) rather than stressing your own political views. Therefore, will you be perceived as being someone who talks and theorises about criticality or works with it and is interested in what it means to practise? However, regardless of your position, be prepared to be perceived by some people in the following way; 'male posturing at conferences', 'top-down worshipping great figures from afar', 
'tribal thing', 'lack of professionalism', 'certainty of some people's critique', 'CMS pedagogy as hippies playing in the sandpit', 'X's management learning a kind of piety', and 'with the more extreme stuff...I am in contempt of it', 'then you have a really good group of people.... brilliant group of people who judge people on the output of their work'.

\section{What are your conditions of practice?}

Your conditions of practice, including position, institution, location, and gender, were found by some to affect your critical aspirations (Hagen et al., 2003; Perriton, 2007; Sinclair, 2007). Are you a senior, male academic, in an elite university or does it make a difference? Many of the educators in the study held senior positions as Professors or Directors of Programmes within their organisations. It was also noted by two educators that position within an organisation might be a factor, which could help or hinder your efforts. One articulated that having a senior position might make it easier to work in this way. Another spoke about how being male with a senior position was a characteristic of key critical educators. It was found that although most of the female educators held less senior positions in their organisations: they were mostly found to engage in the more process-oriented forms of critical teaching. Does this resonate with Bierema (2009) in her conceptualisation of the dominant masculine rationality? The relevance of organisational cultural and political values (Bennis and O'Toole, 2005; Thomas, 2007), as discussed previously, would also be relevant factors to be aware of in developing your critical aspirations. Resistance and challenges may be experienced depending on the organisational and Business School culture. As a result, further research on criticality could be undertaken in the elite and non-elite universities, inside and outside the UK and between different genders and positions. However, even though most of the educators are now working in the elite UK universities, many of them had experience of working in different educational environments. For some, it was while working in community education, further education, and adult education, as well as in the non-elite universities, that they had experienced or worked in a critical way. However, regardless of the conditions of practice, all the interviewees had found an outlet for their criticality regardless of what those conditions were. They had found institutional support or support through fellow colleagues or external networks. Such collegial support would be particularly relevant for those who are new to the field or for the field that is less prominent in their organisations or country.

\section{What teaching methodologies will you use?}

Teaching in a critical way was found to be less about imparting skills and competencies (Holman, 2000) and more about a different understanding of learning. How will this philosophy of learning be communicated and previous learning be deconstructed, as observed in the study? Will it be something that emerges over time or is articulated from the beginning of the learning process? Consideration must be made for the teaching methodologies that you use. From the findings, most of the educators were focussed more on the process of learning. Experiential methods using group work and action learning were prominent. Lecturing was less used, but when it was, it was powerful and well positioned. Uses of dialogue and communication skills are important for critical educators. In particular, facilitation skills were crucial for those using the more experiential methods like action learning. Having psychodynamic skills and being co-trained with experienced critical educators were characteristics of some of the more process-oriented educators. The tutor's role in creating the environment wherein critical learning evolves is important. The action learning sets facilitated this, and a learning community (Brookfield, 1994) was formed. However, there are potential challenges of teaching in this way. These include student audience, culture, and resources (Choo, 2007b). Educators regarded it as being relatively easier to teach postgraduates rather than undergraduates. However, most of the educators in the study teach postgraduates and those that do teach undergraduates did not see it as being any more of a challenge. Large class sizes, teaching workloads, and an absence of critical textbooks were also seen to constrain a critical approach.

\section{What will be the effect of your critical teaching?}

The outcome of teaching critically may result in the making of students who embrace this way of teaching in a positive way. For some students, it may legitimise and vindicate their thinking. It may even empower them not only during their studies but also in their own organisations (Lawless and McQue, 2008). The establishment of action learning groups or networks outside the classroom could be a further extension of their learning. Teaching in this way can make a difference, but the student may not see this at the time. The relevancy or benefits of their learning may often be months or years later. The experience may not be pleasant for everyone. It may generate feelings of anxiety and unexplored emotions. A key characteristic of anxiety is that it has both paralysing and productive effects (Vince, 2010). 


\section{CONCLUSIONS AND IMPLICATIONS}

The research questions explored how criticality is perceived and experienced by critical educators. The findings show that critical educators are not all the same and their orientation to practice can emphasise a political, theoretical, and/or a practical perspective. With regard to the effect on teaching, the focus on content and/or process had implications for how critical educators practised. From the analysis, it can be seen that there are two types of critical educators emerging from the data based on their focus on the content and process of their practice. These are the critical experientialists and the critical traditionalists. The research contributes to both the knowledge and the practice of criticality. It contributes to the field of management education wherein critical practice is less prominent. It also contributes to other fields of education wherein educators want to learn more about criticality. This is particularly relevant to educators like me, who are new to the field or work in organisations in which it is less prevalent. The research has shown both the benefits and challenges of engaging in such an approach. A CME course can help educators and students reveal the complexities of management and its impact on society. It can legitimise their thinking and provide a way to articulate it. However, educating in this way has its challenges from both inside and outside the classroom. There may be anxieties and resistance to this form of learning, which the analysis has revealed. However, the classroom dynamics of action learning and other experiential exercises can be powerful in creating an organisation in the classroom. However, the research also reveals how important the role of the tutor is in preparing, creating, and facilitating the critical learning environment. This environment has the potential for enabling tomorrow's critical managers to emerge. Overall, the research provides an understanding of the critical classroom to the educator so that they can be better prepared. The ideal types contribute to knowledge in that they highlight exemplars of different ways of being critical dependent on the individual's own perceptions, temperaments, and conditions of practice. The evidence demonstrates that it is possible to develop hybrid or alternative models of teaching and learning in business education without undermining quality or the need for content.

\section{References}

Alvesson, M. and Willmott, H. (2003). Studying Management Critically, London: Sage.

Bennis, W.G. and O'Toole, J. (2005). 'How business schools lost their way'. Harvard Business Review, May/June, 96-104.

Bierema, L. (2009). 'Critical human resource development dominant masculine rationality and evaluating its impact'. Human Resource Development Review, 8: 1, 68-96.

Brookfield, S. (1994). 'Tales from the dark side: A phenomenography of adult critical education'. International Journal of Lifelong Education, 13: 3, 203-216.

Choo, K.L. (2007a). 'The implications of introducing critical management education to Chinese students studying in UK Business Schools: Some empirical evidence'. Journal of Further and Higher Education, 31: 2, 145-148.

Choo, K.L. (2007b). 'Can critical management education be critical in a formal higher educational setting?'. Teaching in Higher Education, 12: 4, 485-497.

Collin, A. (1996). 'The MBA: The potential for students to find their voice in Babel', in R. French and D. Grey (eds), Rethinking Management Education, London: Sage, pp.132-152.
Currie, G. and Knights, D. (2003). 'Reflecting on a critical pedagogy in MBA education'. Management Learning, 24: 1, 27-49.

Engwall, L. (2007). 'The anatomy of management education'. Scandinavian Journal of Management, 23: 1, 4-35.

Fournier, V. and Grey, C. (2000). 'At the critical moment: Conditions and prospects for critical management studies'. Human Relations, 53: 1, 7-32.

Giroux, H. (1981). Ideology, Culture, and the Process of Schooling, Philadelphia, PA: Temple University Press.

Grey, C. and Mitev, N. (1995). 'Management education a polemic'. Management Learning, 26: 1, 73-90.

Hagen, R., Miller, S. and Johnson, M. (2003). 'The 'disruptive consequences' of introducing a critical management perspective onto an MBA programme: The lecturers' view'. Management Learning, 34: 2, 241-257.

Hancock, P. (2008). 'Critical management studies: An introduction'. Critical Sociology, 34: 1, 9-14.

Holman, D. (2000). 'Contemporary models of management education in the UK'. Management Learning, 31: 2, 197-217.

Korpiaho, K., Paivio, H. and Rasanen, K. (2007). 'Anglo-American forms of management education: 
A practice-theoretical perspective'. Scandinavian Journal of Management, 23: 1, 36-65.

Lawless, A. and McQue, L. (2008). 'Becoming a community of critically reflective HR practitioners: Challenges and opportunities within an MA partnership programme'. Journal of European Industrial Training, 32: 5, 323-335.

McLean, M. (2006). Pedagogy and the University Critical Theory and Practice, London: Continuum Press.

Mintzberg, H. (2004). Managers not MBAs, New York: Prentice Hall.

Monaghan, C.H. and Cervero, R.M. (2006). 'Impact of critical management studies courses on learners' attitudes and beliefs'. Human Resource Development International, 9: 3, 379-396.

Perriton, L. (2007). 'Really useful knowledge? Critical management education in the UK and the US'. Scandinavian Journal of Management, 23: 1, 6683.

Perriton, L. and Reynolds, M. (2004). 'Critical management education: From pedagogy of possibility to pedagogy of refusal?' Management Learning, 35: 1, 61-78.

Podolny, J.M. (2009). 'The buck stops (and starts) at Business Schools'. Harvard Business Review, 87: 6, 62-67.

Reynolds, M. (1997). 'Toward a critical management pedagogy', in J. Burgoyne and M. Reynolds (eds), Management Learning: Integrating Perspectives in Theory and Practice, London: Sage, p.312.

Reynolds, M. (1999). 'Grasping the Nettle: Possibilities and pitfalls of a critical management pedagogy'.
British Journal of Management, 9, 171-184.

Reynolds, M. and Trehan, K. (2001). 'Classroom as real world: Propositions for a pedagogy of difference'. Gender and Education, 13: 4, 357-372.

Rigg, C. and Trehan, K. (1999). 'Not critical enough? Black women raise challenges for critical management learning'. Gender and Education, 11: 3, 263-280.

Sinclair, A. (2007). 'Teaching leadership critically to MBAs: Experiences from heaven and hell'. Management Learning, 38: 4, 458-472.

Thomas, H. (2007). 'Guest editorial'. Journal of Management Development, 26: 1.

Vince, R. and Reynolds, M. (2007). 'Introduction: Experiential learning and management education: Key themes and future directions', in M. Reynolds and R. Vince (eds), The Handbook of Experiential Learning \& Management Education, Oxford: Oxford University Press.

Vince, R. (2010). 'Anxiety, politics and critical management education'. British Journal of Management, 21: S1, 26-39.

Watson, T. (2007). 'Work orientations and management practices: An experiential and theoretical learning event' in M. Reynolds and R. Vince (eds), The Handbook of Experiential Learning and Management Education, Oxford: Oxford University Press.

Wellington, J. and Szczerbinski, M. (2007). Research Methods for the Social Sciences, London: Continuum Publishing. 